\title{
10. Literaturverzeichnis
}

Bei Quellen, die gleichermassen in einer Druckversion und elektronisch im ArXiv (http://arXiv.org) verfügbar sind, beziehen sich die Seitenangaben der Zitate im allgemeinen auf die Seitenzählung der PDF-Formatierung des elektronischen Archiveintrags.

Aaronson, S., 2004: Is Quantum Mechanics an Island in Theoryspace?, arXiv: quant-ph/0401062

Aaronson, S., 2004a: Limits on Efficient Computation in the Physical

World, Dissertation, University of California, Berkeley, arXiv: quant$\mathrm{ph} / 0412143$

Aaronson, S., 2004b: Quantum Computing, Postselection, and Probabilistic Polynomial-Time, arXiv: quant-ph/0412187

Aaronson, S., 2005: NP-Complete Problems and Physical Reality, arXiv: quant-ph/0502072

Acharya, B.S. / Douglas, M.R., 2006: A Finite Landscape?, arXiv: hepth/0606212

Aguirre, A., 2005: On making Predictions in a Multiverse: Conundrums,

Dangers, and Coincidences, arXiv: astro-ph/0506519

Aguirre, A. / Tegmark, M., 2005: Multiple Universes, Cosmic

Coincidences, and other Dark Matters, Journal of Cosmology and

Astroparticle Physics 0501, 003, arXiv: hep-th/0409072

Aharony, O. / Gubser, S.S. / Maldacena, J. / Ooguri, H. / Oz, Y., 1999:

Large N Field Theories, String Theory and Gravity, Physics Reports

323, 183-386, arXiv: hep-th/9905111

Aitchinson, I.J.R., 1982: An Informal Introduction to Gauge Field Theory, Cambridge

Alvarez-Gaumé, L. / Vazquez-Mozo, M.A., 1995: Topics in String Theory and Quantum Gravity, in: J. Zinn-Justin / B. Julia (Eds.): Les

Houches Summer School on Gravitation and Quantizations, 1992, Amsterdam, 481-636, arXiv: hep-th/9212006

Alwis, S.P. de, 2006: Transition between Flux Vacua, arXiv: hepth/0605184

Amati, D. / Ciafaloni, M. / Veneziano, G., 1989: Can spacetime be probed below the string size?, Physics Letters B 216, 41-47 
Amelino-Camelia, G. / Arzano, M. / Procaccini, A., 2004: A glimpse at the flat-spacetime limit of quantum gravity using the Bekenstein argument in reverse, International Journal of Modern Physics D 13, 2337-2343, arXiv: hep-th/0506182

Antoniadis, I., 2001: Physics with Large Extra Dimensions - String Theory under Experimental Test, Current Science 81(12), 1609-1613

Antoniadis, I. / Arkani-Hamed, N. / Dimopoulos, S. / Dvali, G., 1998: New Dimensions at a Millimeter to a Fermi and Superstrings at a TeV, Physics Letters B 436, 257ff, arXiv: hep-th/9804398

Argyres, P.: Introduction to Global Supersymmetry, http://www.physics.uc.edu/ argyres/661/

Arkani-Hamed, N. / Dimopoulos, S., 2005: Supersymmetric Unification without Low Energy Supersymmetry and Signatures for Fine-Tuning at the LHC, Journal of High Energy Physics 0506, 073, arXiv: hepth/0405159

Arkani-Hamed, N. / Dimopoulos, S. / Dvali, G., 1998: The Hierarchy Problem and New Dimensions at a Millimeter, Physics Letters B 429, 263ff, arXiv: hep-th/9803315

Arkani-Hamed, N. / Dimopoulos, S. / Dvali, G., 2000: Die unsichtbaren Dimensionen des Universiums, Spektrum der Wissenschaft (10/2000), 44-51

Arkani-Hamed, N. / Dimopoulos, S. / Giudice, G.F., 2005: Aspects of Split Supersymmetry, Nuclear Physics B 709, 3-46, arXiv: hep-ph/0409232 Ashtekar, A., 1984: Asymptotic Quantization, Naples; auch: http://cgpg.gravity.psu.edu/research/asymquant-book.pdf Ashtekar, A., 1986: New Variables for Classical and Quantum Gravity, Physical Review Letters 57, 2244-2247

Ashtekar, A., 1987: New Hamiltonian Formulation for General Relativity, Physical Review D 36, 1587-1602

Ashtekar, A., 1991: Lectures on Non-Perturbative Canonical Gravity, Singapore

Ashtekar, A., 2000: Quantum Mechanics of Geometry, in: N. Dadhich / A. Kembhavi (Eds.): The Universe - Visions and Perspectives, Dordrecht, arXiv: gr-qc/9901023

Ashtekar, A., 2002: Quantum Geometry in Action: Big Bang and Black Holes, arXiv: math-ph/0202008

Ashtekar, A., 2005: Gravity and the Quantum, New Journal of Physics 7, 198, arXiv: gr-qc/0410054 
Ashtekar, A., 2006: Gravity, Geometry and the Quantum, arXiv: grqc/0605011

Ashtekar, A. / Geroch, R., 1974: Quantum Theory of Gravitation, Reports on Progress in Physics 37, 1211-1256

Ashtekar, A. / Lewandowski, J., 1999: Quantum Field Theory of Geometry, in: T.Y. Cao (Ed.): Conceptual Foundations of Quantum Field Theory, Cambridge, 187-206

Ashtekar, A. / Lewandowski, J., 2004: Background Independent Quantum Gravity - A Status Report, Classical and Quantum Gravity 21, R53, arXiv: gr-qc/0404018

Ashtekar, A. / Pawlowski, T. / Singh, P., 2006: Quantum Nature of the Big Bang, Physical Review Letters 96, 141301, arXiv: gr-qc/0602086 Ashtekar, A. / Rovelli, C. / Smolin, L., 1992: Weaving a Classical Metric with Quantum Threads, Physical Review Letters 69, 237-240

Aspinwall, P.S., 1996: Some Relationships Between Dualities in String Theory, Nuclear Physics Proceedings Supplement 46, 30-38, arXiv: hep-th/9508154

Aspinwall, P.S., 2004: D-Branes on Calabi-Yau Manifolds, arXiv: hepth/0403166

Aspinwall, P.S. / Greene, B.R. / Morrison, D.R., 1994: Calabi-Yau Moduli Space, Mirror Manifolds and Spacetime Topology Change in String

Theory, Nuclear Physics B 416, 414, arXiv: hep-th/9309097

Auyang, S.Y., 1995: How is Quantum Field Theory Possible?, Oxford Auyang, S.Y., 2001: Spacetime as a Fundamental and Inalienable Structure of Fields, Studies in History and Philosophy of Modern Physics 32, 205-215

Bachas, C., 1996: D-Brane dynamics, Physics Letters B 374, 37, arXiv: hep-th/9511043

Bachas, C., 1997: (Half) A Lecture on D-Branes, arXiv: hep-th/9701019

Bailin, D. / Love, A., 1994: Supersymmetric Gauge Field Theory and String Theory. Bristol and Philadelphia

Bak, D. / Rey, S.-J., 2000: Holographic Principle and String Cosmology, Classical and Quantum Gravity 17, L1, arXiv: hep-th/9811008

Bak, D. / Rey, S.-J., 2000a: Cosmic Holography, Classical and Quantum Gravity 17, L83, arXiv: hep-th/9902173

Balasubramanian, V. / Jejjala, V. / Simón, J., 2005: The Library of Babel, International Journal of Modern Physics D 14, 2181-2186, arXiv: hep-th/0505123 
Balasz, L.A.P., 1986: Could there be a Planck-Scale Unitary Bootstrap Underlying the Superstring, Physical Review Letters 56, 1759-1762 Balzer, W. / Pearce, D.A. / Schmidt, H.-J. (Eds.), 1984, Reduction in Science: Structures, Examples, Philosophical Problems, Dordrecht Banks, T., 1988: Prolegomena to a Theory of Bifurcating Universes - A Nonlocal Solution to the Cosmological Constant Problem or Little Lambda goes to the Future, Nuclear Physics B 309, 493-512 Banks, T., 1998: Matrix Theory, Nuclear Physics Proceedings Supplement B 67, 180-224, arXiv: hep-th/9710231

Banks, T., 2000: On Isolated Vacua and Background Independence, arXiv: hep-th/0011255

Banks, T., 2001: Cosmological Breaking of Supersymmetry or Little Lambda goes back to the Future II, International Journal of Modern Physics A 16, 910, arXiv: hep-th/0007146

Banks, T., 2001a: TASI Lectures on Matrix Theory, in: Harvey / Kachru / Silverstein (2001), arXiv: hep-th/9911068

Banks, T., 2002: Heretics of the False Vacuum - Gravitational Effects On and Of Vacuum Decay 2., arXiv: hep-th/0211160

Banks, T., 2003: A Critique of Pure String Theory: Heterodox Opinions of Diverse Dimensions, arXiv: hep-th/0306074

Banks, T., 2004: Landscepticism or Why Effective Potentials Don't Count String Models, arXiv: hep-th/0412129

Banks, T. / Dine, M. / Gorbatov, E., 2004: Is there a String Theory Landscape?, Journal of High Energy Physics 0408, 058, arXiv: hepth/0309170

Banks, T. / Dine, M. / Motl, L., 2001: On Anthropic Solutions of the Cosmological Constant Problem, Journal of High Energy Physics 0101, 031, arXiv: hep-th/0007206

Banks, T. / Douglas, M.R. / Seiberg, N., 1996: Probing F-Theory with Branes, Physics Letters B 387, 278-281, arXiv: hep-th/9605199

Banks, T. / Fischler, W., 2001: M-Theory Observables for Cosmological Space-times, arXiv: hep-th/0102077

Banks, T. / Fischler, W., 2001a: A Holographic Cosmology, arXiv: hepth/0111142

Banks, T. / Fischler, W., 2005: Holographic Cosmology 3.0, Physica Scripta T 117, 56-63, arXiv: hep-th/0310288

Banks, T. / Fischler, W. / Shenker, S.H. / Susskind, L, 1997: M Theory as a Matrix Model: A Conjecture, Physical Review D 55, 5112-5128, arXiv: hep-th/9610043 
Barbón, J.L.F., 2004: String Theory, European Physics Journal C 33, 567574, arXiv: hep-th/0404188

Barbour, J., 1999: The End of Time. The Next Revolution in Physics, London

Barbour, J., 2001: On general covariance and best matching, in: Callender / Huggett (2001)

Barbour, J. / Pfister, H., 1995: Mach's Principle: From Newton's Bucket to Quantum Gravity, Boston

Bardeen, J.M. / Carter, B. / Hawking, S.W., 1973: The Four Laws of Black Hole Mechanics, Communications in Mathematical Physics 31, 161170

Barnard, M. / Albrecht, S., 2004: On open inflation, the string theory landscape and the low CMB quadrupole, 123509, arXiv: hepth/0409082

Barrow, J.D., 1991: Theories of Everything, Oxford Barrow, J.D., 1992: Pi in the Sky, Oxford

Barrow, J.D., 1995: Theories of Everything, in: Hilgevoord (1995)

Barrow, J.D., 2000: The Book of Nothing: Vacuums, Voids and the Latest Ideas about the Origin of the Universe, New York

Barrow, J.D., o.J.: Living in a Simulated Universe, http://www.simulationargument.com

Barrow, J.D. / Davies, P.C.W. / Harper, C.L. (Eds.), 2004: Science and Ultimate Reality: Quantum Theory, Cosmology, and Complexity, Cambridge

Barrow, J.D. / Tipler, F.J., 1986: The Anthropic Cosmological Principle, Oxford

Bartels, A., 1994: Von Einstein zu Aristoteles - Raumzeit-Philosophie und Substanz-Metaphysik, Philosophia Naturalis 31, 294-308

Bartels, A., 1996: Modern Essentialism and the Problem of Individuation of Spacetime Points, Erkenntnis 45, 25-43

Bartels, A., 1999: Objects or Events?: Towards an Ontology for Quantum

Field Theory, Philosophy of Science 66, Supplement (Proceedings), S170-S184

Becher, P. / Böhm, M. / Joos, H., 1981: Eichtheorien der starken und elektroschwachen Wechselwirkung, Stuttgart

Bekenstein, J.D., 1973: Black Holes and Entropy, Physical Review D 7, 2333-2346

Bekenstein, J.D., 1974: Generalized Second Law of Thermodynamics in Black Hole Physics, Physical Review D 9, 3292-3300 
Bekenstein, J.D., 1981: Universal Upper Bound on the Entropy-to-Energy Ratio for Bounded Systems, Physical Review D 23, 287-298

Bekenstein, J.D., 2000: Holographic Bound from Second Law, arXiv: grqc/0007062

Bekenstein, J.D., 2001: The Limits of Information, Studies in the History and Philosophy of Modern Physics 32, 511-524, arXiv: gr-qc/0009019

Bekenstein, J.D., 2003: Das holografische Universum, Spektrum der Wissenschaft (11/2003), 34-41

Belot, G., 1996: Whatever is Never and Nowhere is Not: Space, Time, and Ontology in Classical and Quantum Gravity, Dissertation, University of Pittsburgh, Pittsburgh

Belot, G., 2000: Geometry and Motion, British Journal for the Philosophy of Science 51, 561-595

Belot, G. / Earman, J., 1999: From metaphysics to physics, in: Butterfield / Pagonis (1999)

Belot, G. / Earman, J., 2001: Pre-socratic quantum gravity, in: Callender / Huggett (2001)

Belot, G. / Earman, J., / Ruetsche, L., 1999: The Hawking Information Loss Paradox: The Anatomy of a Controversy, British Journal for the Philosophy of Science 50, 189-229

Bertola, F. / Curi, U. (Eds.), 1993: The Anthropic Principle, Cambridge Bettini, S., 2005: Anthropic Reasoning in Cosmology: A Historical Perspective, in: M. Stöltzner / P. Weingartner (Hg.): Formale Teleologie und Kausalität in der Physik, Paderborn

Bettini, S., o.J.: Il Labirinto Antropico, http://www.swif.uniba.it/lei/saggi/antropico http://www.swif.it/biblioteca/cxc/

Bigatti, D. / Susskind, L., 1997: Review of Matrix Theory, arXiv: hepth/9712072

Bigatti, D. / Susskind, L., 2001: TASI Lectures on the Holographic Principle, in: Harvey / Kachru / Silverstein (2001), arXiv: hep-th/0002044

Bilal, A., 1999: M(atrix) Theory - A Pedagogical Introduction, Fortschritte der Physik 47, 5-28, arXiv: hep-th/9710136

Bilson-Thompson, S.O. / Markopoulou, F. / Smolin, L., 2006: Quantum Gravity and the Standard Model, arXiv: hep-th/0603022

Blanchard, P. / Giulini, D. / Joos, E. / Kiefer, C. / Stamatescu, I.-O. (Eds.), 2000: Decoherence: Theoretical, Experimental, and Conceptual Problems, Heidelberg 
Blasche, S. et al. (Hrsg.), 1992: Realismus und Antirealismus, Frankfurt am Main

Boehmer, C.G. / Harko, T., 2006: Physics of Dark Energy Particles, arXiv: gr-qc/0602081

Boer, J.de / Dijkgraaf, R. / Hori, K. / Keurentjes, A. / Morgan, D.R. / Sethi, S., 2002: Triples, Fluxes, and Strings, Advances of Theoretical and Mathematical Physics 4, 995, arXiv: hep-th/0103170

Bojowald, M., 2001: Quantum Geometry and Symmetry, Aachen

Bojowald, M., 2004: Loop Quantum Cosmology - Recent Progress, arXiv: gr-qc/0402053

Bojowald, M., 2005: Nonsingular Black Holes and Degrees of Freedom in

Quantum Gravity, Physical Review Letters 95, 061301, arXiv: grqc/0506128

Bojowald, M., 2006: Loop Quantum Cosmology, Living Reviews in Relati-

vity (Electronic Journal), http://www.livingreviews.org, auch: arXiv: gr-qc/0601085

Bojowald, M., 2006a: Quantum Riemannian Geometry and Black Holes, arXiv: gr-qc/0602100

Bojowald, M., 2006b: Quantum Cosmology, arXiv: gr-qc/0603110

Bojowald, M. / Morales-Tecotl, H.A., 2004: Cosmological Applications of Loop Quantum Gravity, in: Lecture Notes in Physics 646, 421-462, arXiv: gr-qc/0306008

Bokulich, P., 2001: Black Hole Remnants and Classical vs. Quantum

Gravity, Philosophy of Science (Proceedings), 68, S407-S423

Bousso, R., 2002: The Holographic Principle, Reviews of Modern Physics

74, 825-874, arXiv: hep-th/0203101

Bousso, R., 2006: Holographic Probabilities in Eternal Inflation, arXiv: hep-th/0605263

Bousso, R. / Polchinski, J., 2000: Quantization of Four-form Fluxes and

Dynamical Neutralization of the Cosmological Constant, Journal of

High Energy Physics 0006, 006, arXiv: hep-th/0004134

Bousso, R. / Freivogel, B. / Lippert, M., 2006: Probabilities in the Landscape: The Decay of Nearly Flat Space, arXiv: hep-th/0603105

Bostrom, N., 2002: Anthropic Bias: Observation Selection Effects in

Science and Philosophy, New York

Bostrom, N., 2003: Are You Living in a Computer Simulation?, Philosophical Quarterly 53, 243-255, http://www.simulation-argument.com Boyd, N., 1983: On the current status of scientific realism, Erkenntnis 19, 45-90 
Boyd, R., 1990: Realism - Approximate Truth and Philosophical Method, in: S.W. Savage: Scientific Theories, Minnesota Studies in the Philosophy of Science 14, 355ff

Braun, V. / He, Y.-H. / Ovrut, B.A. / Pantev, T., 2006: The Exact MSSM Spectrum from String Theory, Journal of High Energy Physics 0605, 043, arXiv: hep-th/0512177

Braunstein, S.L. / Pati, A.K., 2006: Quantum Information cannot be completely hidden in correlations: Implications for the Black-Hole Information Paradox, arXiv: gr-qc/0603046

Brax, P. / Bruck, C. van der, 2003: Cosmology and Brane Worlds - A Review, Classical and Quantum Gravity 20, R201-R232, arXiv: hepth/0303095

Breuer, T., 1997: Universell und unvollständig: Theorien über alles?, Philosophia Naturalis 34, 1-20

Brown, H.R. / Harre, R. (Eds.), 1988: Philosophical Foundations of Quantum Field Theory, Oxford

Brunetti, R. / Fredenhagen, K., 2006: Towards a Background Independent Formulation of Perturbative Quantum Gravity, arXiv: gr-qc/0603079 Brustein, R. / de Alwis, S.P., 2006: The Landscape of String Theory and The Wave Function of the Universe, Physical Review D 73, 046009 , arXiv: hep-th/0511093

Burgess, C.P., 2004: Quantum Gravity in Everyday Life - General Relativity as an Effective Field Theory, Living Reviews in Relativity

(Electronic Journal), http://www.livingreviews.org/lrr-2004-5

Burgess, C.P., 2006: Strings, Branes and Cosmology - What can we hope to learn?, arXiv: hep-th/0606020

Butterfield, J., 1989: The Hole Truth, British Journal for the Philosophy of Science 40, 1-28

Butterfield, J., 2002: Julian Barbour: The End of Time - Critical Notice, British Journal for the Philosophy of Science 53, 289-330

Butterfield, J. / Hogarth, M. / Belot, G. (Eds.), 1996: Spacetime, Aldershot Butterfield, J. / Isham, C., 1999: On the Emergence of Time in Quantum Gravity, in: J. Butterfield (Ed.): The Arguments of Time, Oxford, 111168; auch: arXiv: gr-qc/9901024

Butterfield, J. / Isham, C., 2001: Spacetime and the Philosophical Challenge of Quantum Gravity, in: Callender / Huggett (2001) Butterfield, J. / Pagonis, C. (Eds.), 1999: From Physics to Philosophy, Cambridge 
Callender, C. / Huggett, N. (Eds.), 2001: Physics meets Philosophy at the

Planck Scale. Contemporary Theories of Quantum Gravity,

Cambridge

Callender, C. / Huggett, N., 2001a: Introduction, in: Callender / Huggett (2001)

Callender, C. / Huggett, N., 2001b: Why quantize Gravity (or any other

field for the matter)?, Philosophy of Science (Proceedings), 68, S382-

S394

Callender, C. / Weingard, R., 2000: Topology Change and the Unity of

Space, Studies in the History and Philosophy of Modern Physics 31,

227-246

Calmet, X. / Graesser, M. / Hsu, S.D.H., 2005: Minimum Length from

First Principles, International Journal of Modern Physics D 14, 2195 -

2200, arXiv: hep-th/0505144

Candelas, P., 1988: Lectures of Complex Manifolds, in: L. Alvarez-Gaumé et al.: Superstrings ' 87 , Singapore, 1-88

Candelas, P. / Horowitz, G.T. / Strominger, A. / Witten, E., 1985: Vacuum

Configurations for Superstrings, Nuclear Physics B 258, 46ff

Candelas, P. / Ossa, X.C. de la, 1991: Moduli Space of Calabi-Yau

Manifolds, Nuclear Physics B 355, 455-481

Cao, T.Y. (Ed.), 1999: Conceptual Foundations of Quantum Field Theory,

Cambridge

Cao, T.Y., 1999a: Introduction: Conceptual Issues in Quantum Field

Theory, in: T.Y. Cao (Ed.): Conceptual Foundations of Quantum

Field Theory, Cambridge

Cao, T.Y., 2001: Prerequisites for a Consistent Framework of Quantum

Gravity, Studies in History and Philosophy of Modern Physics 32, 181-204

Cao, T.Y., 2003: Can We Dissolve Physical Entities into Mathematical

Structures?, Synthese 136/1, 57-71

Cao, T.Y., 2003a: What is Ontological Synthesis? - A Reply to Simon

Saunders, Synthese 136/1, 107-126

Carlip, S., 2001: Quantum Gravity: A Progress Report, Reports on

Progress in Physics 64, 885, arXiv: gr-qc/0108040

Carroll, S.M., 2000: The Cosmological Constant, Living Reviews in

Relativity (Electronic Journal), http://www.livingreviews.org; auch:

arXiv: astro-ph/0004075

Carroll, S.M., 2005: Is Our Universe Natural?, arXiv: hep-th/0512148

Carter, B., 2006: Anthropic Principle in Cosmology, arXiv: gr-qc/0606117 
Cartwright, N., 1983: How the Laws of Physics lie, Oxford

Cartwright, N., 1989: Nature's Capacities and Their Measurement, Oxford Cartwright, N., 1994: Fundamentalism vs the Patchwork of Laws,

Proceedings of the Aristotelian Society 93, 279-292

Cartwright, N., 1995: Precis of Nature's Capacities and Their

Measurement, Philosophy and Phenomenological Research LV/1, 153-161

Cartwright, N., 1999: The Dappled World, Cambridge

Caticha, A., 2005: The Information Geometry of Space and Time, arXiv: gr-qc/0508108

Chalmers, D.J., o.J.: The Matrix as Metaphysics, http://consc.net/papers/matrix.html

Chew, G.F., 1963: The Dubious Role of the Space-Time Continuum in Microscopic Physics, Science Progress 51, 529-539

Chew, G.F., 1968: Bootstrap - A Scientific Idea?, Science 161, 762-765

Chew, G.F., 1970: Hadron Bootstrap - Triumph or Frustration?, Physics Today 23/10, 23-28

Chew, G.F., 1983: The Topological Bootstrap, in: A.H. Guth / K. Huang / R.L. Jaffe (Eds.): Asymptotic Realms of Physics, Cambridge, Ma.

Chiao, R.Y., 2004: Conceptual Tensions between Quantum Mechanics and General Relativity: Are there Experimental Consequences?, in: Barrow / Davies / Harper (2004), 254-279

Chu, Chong-Sun / Lechtenfeld, O., 2006: Emergence of Time from Dimensional Reduction in Noncommutative Geometry, Modern Physics Letters A 21, 639-648, arXiv: hep-th/0508055

Churchland, P.M. / Hooker, C.A. (Eds.), 1985: Images of Science, Chicago Clavelli, L., 2005: Properties of a Future Susy Universe, arXiv: hepth/0508207

Coleman, S.R., 1988: Why there is Nothing rather than Something: A Theory of the Cosmological Constant, Nuclear Physics B 310, 643668

Coleman, S.R. / De Luccia, F., 1980: Gravitational Effects on and of Vacuum Decay, Physical Review D 21, 3305-3315

Collins, G.P., 1997: Quantum Black Holes are tied to D-Branes and Strings, Physics Today 50/3, 19-22

Collins, J.C., 2006: Renormalization: General Theory, arXiv: hepth/0602121 
Conlon, J.P. / Quevedo, F., 2004: On the explicit construction and statistics of Calabi-Yau flux vacua, Journal of High Energy Physics 0410, 039, arXiv: hep-th/0409215

Connes, A., 1998: Noncommutative Differential Geometry and the Structure of Space-Time, in: S.A. Huggett et al. (Eds.): The Geometric Universe, Oxford (1998)

Crane, L., 2001: A New Approach to the Geometrization of Matter, arXiv: gr-qc/0110060

Cremmer, E. / Julia, B. / Scherk, J., 1978: Supergravity Theory in Eleven Dimensions, Physics Letters B 76, 409-412

Curiel, E., 2001: Against the Excess of Quantum Gravity: A Plea for Modesty, Philosophy of Science (Proceedings), 68, S424-S441

Cushing, J.T., 1985: Is there just One Possible World? Contingency vs. the Bootstrap, Studies in History and Philosophy of Science 16, 31-48

Cushing, J.T., 1988: Foundational Problems in and Methodological Lessons from Quantum Field Theory, in: Brown / Harré (1988)

Dadhich, N., 2006: A Unified View of the Basic Forces, arXiv: gr$\mathrm{qc} / 0605074$

Dainton, B., 2002: Innocence Lost - Simulation Scenarios: Prospects and

Consequences, http://www.simulation-argument.com

Dambmann, H., 1990: Die Bedeutung des Machschen Prinzips in der

Kosmologie, Philosophia Naturalis 27, 234-271

Das, S.R. / Mathur, S.D., 2001: The Quantum Physics of Black Holes -

Results from String Theory, Annual Reviews of Nuclear Particle

Science 50, 153-206, arXiv: gr-qc/0105063

David, J.R. / Mandal, G. / Wadia, S.R., 2002, Microscopic Formulation of

Black Holes in String Theory, Physics Reports 369, 549-686, arXiv: hep-th/0203048

Davies, P. / Brown, J.R., 1992: Superstrings. Eine Allumfassende Theorie der Natur in der Diskussion, München

Dawid, R., 1999: A Speculative Remark on Holography, Physics Letters B 451, 19, arXiv: hep-th/9811243

Dawid, R., 2003: Scientific Realism in the Age of String Theory, http://philsci-archive.pitt.edu, Dokument PITT-PHIL-SCI00001240

Dawid, R., 2004: Underdetermination and Theory Succession from a

String Theoretical Perspective, http://philsci-archive.pitt.edu, Dokument PITT-PHIL-SCI00001744

Deligne, P. et al. (Eds.), 1999: Quantum Fields and Strings - A Course for Mathematicians, Providence, 
http://www.math.ias.edu/QFT/fall/index.html http://www.math.ias.edu/QFT/spring/index.html

Denef, F. / Douglas, M.R., 2004: Distributions of Flux Vacua, Journal of High Energy Physics 0405, 072, arXiv: hep-th/0404116

Denef, F. / Douglas, M.R., 2006: Computational Complexity of the

Landscape I, arXiv: hep-th/0602072

Denef, F. / Douglas, M.R / Florea, B., 2004: Building a better Racetrack, Journal of High Energy Physics 0406, 034, arXiv: hep-th/0404257

DeWitt, B.S., 1967: Quantum Theory of Gravity. I. The Canonical Theory, Physical Review 160, 1113-1148

DeWitt, B.S., 1967a: Quantum Theory of Gravity. II. The Manifestly Covariant Theory, Physical Review 162, 1195-1239

DeWitt, B.S., 1967b: Quantum Theory of Gravity. III. Applications of the Covariant Theory, Physical Review 162, 1239-1256

DeWitt, B.S., 1972: Covariant Quantum Geometrodynamics, in: J.R. Klauder (Ed.): Magic without Magic - John Archibald Wheeler, San Francisco

DeWitt, B.S., 1999: Quantum Field Theory and Space-Time - Formalism and Reality, in: T.Y. Cao (Ed.): Conceptual Foundations of Quantum Field Theory, Cambridge, 176-186

DeWolfe, O. / Giryavets, A. / Kachru, S. / Taylor, W., 2005: Enumerating Flux Vacua with Enhanced Symmetries, Journal of High Energy Physics 0502, 037, arXiv: hep-th/0411061

Dhar, A., 2001: Non-Critical String Theory, Current Science 81(12), 15981608

Dick, R., 2001: Brane Worlds, Classical and Quantum Gravity 18, R1R24, arXiv: hep-th/0105320

Dieks, D., 2001: Space and Time in Particle and Field Physics, Studies in History and Philosophy of Modern Physics 32, 217-241

Dienes, K.R., 1997: String Theory and the Path to Unification. A Review of Recent Developments, Physics Reports 287, 447-525, arXiv: hepth/9602045

Dienes, K.R., 2006: Statistics on the Heterotic Landscape: Gauge Groups and Cosmological Constants of Four-Dimensional Heterotic Strings, Physical Review D 73, 106010, arXiv: hep-th/0602286

Dijkgraaf, R. / Vafa, C., 2002: A Perturbative Window into NonPerturbative Physics, arXiv: hep-th/0208048

Dine, M., 1997: Supersymmetry Phenomenology (with a broad brush), in: Efthimiou / Greene (1997), 813-882 
Dine, M., 2001: TASI Lectures on M Theory Phenomenology, in: Harvey / Kachru / Silverstein (2001), arXiv: hep-th/0003175

Dine, M., 2004: Is there a String Theory Landscape: Some Cautionary Remarks, arXiv: hep-th/0402101

Dine, M., 2004a: Supersymmetry, Naturalness and the Landscape, arXiv: hep-th/0410201

Dine, M. / Gorbatov, E / Thomas, S., 2004: Low Energy Supersymmetry from the Landscape, arXiv: hep-th/0407043

Dine, M. / O'Neil, D. / Sun, Z., 2005: Branches of the Landscape, Journal of High Energy Physics 0507, 014, arXiv: hep-th/0501214

Dine, M. / Seiberg, N., 1986: Nonrenormalization Theorems in Superstring Theory, Physical Review Letters 57, 2625-2628

Dine, M. / Seiberg, N., 1988: Microscopic Knowledge from Macroscopic Physics in String Theory, Nuclear Physics B 301, 357-380

DiSalle, R., 1994: On Dynamics, Indiscernibility, and Spacetime Ontology, British Journal for the Philosophy of Science 45, 265-287

Douglas, M.R., 1996: Superstring dualities, Dirichlet branes and the small scale structure of space, arXiv: hep-th/9610041

Douglas, M.R., 1998: Gauge Fields and D-Branes, Journal of Geometry and Physics 28, 255-262, arXiv: hep-th/9604198

Douglas, M.R., 2003: The Statistics of String/M Theory Vacua, Journal for High Energy Physics 0305:046, arXiv: hep-th/0303194

Douglas, M.R, 2004: Statistical Analysis of the Supersymmetry Breaking

Scale, arXiv: hep-th/0405279

Douglas, M.R, 2004a: Statistics of String Vacua, arXiv: hep-ph/0401004

Douglas, M.R, 2004b: Basic Results in Vacuum Statistics, Comptes

Rendues Physique 5, 965-977, arXiv: hep-th/0409207

Douglas, M.R., 2006: Understanding the Landscape, arXiv: hepth/0602266

Douglas, M.R. / Kabat, D. / Pouliot, P. / Shenker, S.H., 1997: D-Branes and short distances in String Theory, Nuclear Physics B 485, 85, arXiv: hep-th/9608024

Douglas, M.R. / Taylor, W., 2006: The Landscape of Intersecting Brane Models, arXiv: hep-th/0606109

Dreyer, O., 2006: Emergent General Relativity, arXiv: gr-qc/0604075 Duff, M.J., 1996: M-Theory (the Theory Formerly known as Strings), International Journal of Modern Physics A 11, 5623-5642, arXiv: hep-th/9608117 
Duff, M.J., 1997: Supermembranes, in: Efthimiou / Greene (1997), 219290, arXiv: hep-th/9611203

Duff, M.J., 1998: The Theory Formerly Known as Strings, Scientific American (2/1998), 54-59

Duff, M.J. / Liu, J.T. / Lu, J. (Eds.), 2001: Strings - Proceedings of the 2000 International Superstring Conference, Singapore

Duhem, P., 1908: La theorie physique, son objet et sa structure, Paris (dt.: Ziel und Struktur physikalischer Theorien, Hamburg, 1998)

Dvali, G., 2004: Die geheimen Wege der Gravitation, Spektrum der Wissenschaft (7/2004), 48-55

Earman, J., 1986: Why Space is not a Substance (at least not to the first degree), Australasian Journal of Philosophy 48, 287-319

Earman, J., 1989: World Enough and Spacetime - Absolute Versus Relational Theorie of Space and Time, Cambridge, Ma., MIT Bradford

Earman, J. / Norton, J.D., 1987: What Price Spacetime Substantivalism? The Hole Story, British Journal for the Philosophy of Science 83, 515525

Easther, R. / Greene, B.R. / Jackson, M.G. / Kabat, D., 2005: String Windings in the Early Universe, Journal of Cosmology and Astroparticle Physics 0502, 009, arXiv: hep-th/0409121

Ecker, G., 2005: Effective Field Theories, arXiv: hep-ph/0507056

Efthimiou, C. / Greene, B. (Eds.), 1997: Fields, Strings, and Duality, TASI 1996, Singapore

Egan, G., 1994: Permutation City, London

Ehlers, J. / Friedrich, H. (Eds.), 1994: Canonical Gravity - From Classical to Quantum, Berlin

Eling, C. / Guedens, R. / Jacobson, T., 2006: Non-Equilibrium Thermodynamics of Spacetime, Physical Review Letters 96, 121301, arXiv: gr-qc/0602001

Ellis, G.F. / Kirchner, U. / Stoeger, W.R., 2004: Multiverses and Physical Cosmology, Monthly Notices of the Royal Astronomical Society 347, 921-936, arXiv: astro-ph/0305292

Ellis, J. / Nanopoulos, D.V., 2004: Beyond the Standard Model of Cosmology, arXiv: astro-ph/0411153

Fabinger, M., 2001: Virtual Reality in the World of Holograms, arXiv: hep-th/0104111

Faddeev, L.D. / Popov, V.N., 1967: Feynman Diagrams for the Yang-Mills Field, Physics Letters 25 B, 29-30 
Falkenburg, B., 1988: The Unifying Role of Symmetry Principles in Particle Physics, Ratio (New Series) 1, 113-134

Falkenburg, B., 1993: The Concept of Spatial Structure in Microphysics, Philosophia Naturalis 30, 208-228

Falkenburg, B., 1993a: Substanzbegriff und Quantentheorie, Philosophia Naturalis 30, 229-246

Falkenburg, B., 1993b: Was ist ein Teilchen? Bedeutungen eines fundamentalen physikalischen Konzepts, Physikalische Blätter 49, 403-408

Falkenburg, B., 1993c: Ist es fraglich, ob es Teilchen gibt? Überlegungen zur Debatte um den Wissenschaftlichen Realismus, in: H.J.

Sandkühler (Hrsg.): Konstruktion und Realität.

Wissenschaftsphilosophische Studien, Philosophie und Geschichte der Wissenschaften 22, Frankfurt am Main

Falkenburg, B., 1995: Teilchenmetaphysik - Zur Realitätsauffassung in Wissenschaftsphilosophie und Mikrophysik, 2. Aufl., Heidelberg

Falkenburg, B., 1996: The Analysis of Particle Tracks: A Case for Trust in the Unity of Physics, Studies in the History and Philosophy of Modern Physics 27 (1996), 337-371

Falkenburg, B., 1997: Modelle, Korrespondenz und Vereinheitlichung in der Physik, Dialektik 1, 27-42

Falkenburg, B., 1998: Korrespondenz, Vereinheitlichung und die Grenzen physikalischer Erkenntnis, Logos (Neue Folge) 5, 215-234

Falkenburg, B., 2000: Kants Kosmologie. Frankfurt am Main

Falkenburg, B., 2000a: How to Observe Quarks, in: E. Agazzi / M. Pauri

(Eds.): The Reality of the Unobservable. Dordrecht, 329-341

Falkenburg, B., 2000b: Kants Naturbegriff und die Begründung der modernen Physik, Philosophia Naturalis 37, 409-438

Falkenburg, B., 2002: Symbol and Intuition in Modern Physics, in: M.

Ferrari / I.-O. Stamatescu (Eds.): Symbol and Physical Knowledge, Heidelberg, 149-176

Falkenburg, B., 2002a: Measurement and ontology: What kind of evidence can we have for quantum fields? In: Kuhlmann / Lyre / Wayne (2002), 235-254

Falkenburg, B., 2002b: Metamorphosen des Teilchenkonzepts, Praxis der Naturwissenschaften - Physik in der Schule, Heft 4/51, 14-23

Falkenburg, B., 2002c: Correspondence and the Non-Reductive Unity of Physics, in: C. Mataix / A. Rivadulla (Eds.): Física Cuántica y Realidad - Quantum Physics and Reality, Madrid 
Falkenburg, B., 2004: Grenzen der physikalischen Erklärung, in: Grenzen und Grenzüberschreitungen. XIX. Deutscher Kongress für Philosophie

- Kongressakten (Hauptvorträge)

Falkenburg, B., 2004a: Experience and Completeness in Physical

Knowledge: Variations on a Kantian Theme, Philosophiegeschichte und logische Analyse 7

Faraggi, A.E., 2005: Fictitious Extra Dimensions, arXiv: hep-th/0509054 Fernández de Labastida, J.M., 1998: Knoten in der Physik, Spektrum der Wissenschaft (10/1998), 66-72

Fischler, W. / Susskind, L., 1998: Holography and Cosmology, arXiv: hepth/9806039

Flam, F., 1992: The Quest for a Theory of Everything Hits Some Snags, Science 256, $1518 \mathrm{f}$

Fliessbach, T., 1995: Allgemeine Relativitätstheorie, Heidelberg

Fredenhagen, K. / Rehren, K.-H. / Seiler, E., 2006: Quantum Field Theory:

Where We Are, arXiv: hep-th/0603155

Freivogel, B. / Kleban, M. / Rodríguez Martínez, M. / Susskind, L., 2006:

Observational Consequences of a Landscape, Journal of High Energy

Physics 0603, 039, arXiv: hep-th/0505232

Freivogel, B. / Susskind, L., 2004: A Framework for the Landscape,

Physical Review D 70, 126007, arXiv: hep-th/0408133

French, S. / Ladyman, J., 2003: Remodelling Structural Realism: Quantum

Physics and the Metaphysics of Structure, Synthese 136/1, 31-56

French, S. / Ladyman, J., 2003a: The Dissolution of Objects: Between

Platonism and Phenomenalism, Synthese 136/1, 73-77

French, P.A. et al. (Eds.), 1988: Realism and Antirealism, Minneapolis

Frogatt, C.D. / Nielsen, H.B., 1991: Origin of Symmetries, Singapore

Gale, G., 1974: Chews Monadology, Journal of the History of Ideas 35, 339-348

Gale, G., 1975: Leibniz, Chew, and Wheeler on the Identity of Physical and Philosophical Inquiry, Review of Metaphysics 29, 322-333

Gale, G., 1981: The Anthropic Principle, Scientific American (12/1981), 154

Galison, P., 1995: Theory Bound and Unbound - Superstrings and

Experiment, in: F. Weinert (Ed.): Laws of Nature - Essays on

Philosophical, Scientific and Historical Dimensions, Berlin, 369-408

Galison, P. / Stump, D. (Eds.), 1996: The Disunity of Science: Boundaries,

Contexts and Power, Stanford

Galouye, D.F., 1964: Simulacron-3, New York 
Gambini, R. / Pullin, J., 1996: Loops, Knots, Gauge Theories and Quantum Gravity, Cambridge

Gambini, R. / Pullin, J., 2003: Discrete Quantum Gravity: A Mechanism for Selecting the Value of Fundamental Constants, International Journal of Modern Physics D 12, 1775-1782, arXiv: gr-qc/0306095

Gambini, R. / Pullin, J., 2004: Consistent Discretization and Quantum Gravity, arXiv: gr-qc/0408025

Gambini, R. / Pullin, J., 2005: Classical and Quantum General Relativity:

A New Paradigm, arXiv: gr-qc/0505052

Gambini, R. / Porto, R.A. / Pullin, J., 2005: Fundamental Gravitational

Limitations to Quantum Computing, arXiv: quant-ph/0507262

Gasperini, M. / Veneziano, G., 2003: The Pre-Big Bang Scenario in String

Cosmology, Physics Reports 373, 1-212, arXiv: hep-th/0207130

Gauntlett, J.P., 2000: Brane New Worlds, Nature 404, 28-29

Gauntlett, J.P. / Harvey, J.A. / Liu, J.T., 1993: Magnetic Monopoles in

String Theory, Nuclear Physics B 409, 363, arXiv: hep-th/9211056

Gervais, J.L. / Sakita, B., 1971: Field Theory Interpretation of Supergauges

in Dual Models, Nuclear Physics B 34, 632-639; auch in: Schwarz

(1985)

Gibbons, G.W. / Shellard, E.P.S. / Rankin, S.J. (Eds.), 2003: The Future of Theoretical Physics and Cosmology, Cambridge

Giddings, S.B., 2003: The Fate of Four Dimensions, Physical Review D

68, 026006, arXiv: hep-th/0303031

Giddings, S.B., 2005: Gravity and Strings, arXiv: hep-th/0501080

Giddings, S.B., 2006: Black Hole Information, Unitarity, and Locality, arXiv: hep-th/0605196

Giddings, S.B. / Kachru, S. / Polchinski, J., 2002: Hierarchies from Fluxes in String Compactification, Physical Review D 66, 106006, arXiv: hep-th/0105097

Ginsparg, P. / Glashow, S., 1986: Desperately seeking superstrings?, Physics Today 39/5, 7-9

Giryavets, A. / Kachru, S. / Tripathy, P.K., 2004: On the Taxonomy of Flux Vacua, Journal of High Energy Physics 0408, 002, arXiv: hepth/0404243

Giulini, D. / Kiefer, C. / Lämmerzahl, C. (Eds.), 2003: Quantum Gravity From Theory to Experimental Search, Berlin

Giveon, A. / Kutasov, D., 1999: Brane Dynamics and Gauge Theory, Reviews of Modern Physics 71, 983-1084, arXiv: hep-th/9802067 
Giveon, A. / Porati, M. / Rabinovici, E, 1994: Target Space Duality in

String Theory, Physics Reports 244, 77, arXiv: hep-th/9401139

Gliozzi, F. / Scherk, J. / Olive, D., 1977: Supersymmetry, Supergravity

Theories and the Dual Spinor Model, Nuclear Physics B 122, 253-

290; auch in: Schwarz (1985)

Goldberger, W.D. / Rothstein, I.Z., 2006: Towers of Gravitational

Theories, arXiv: hep-th/0605238

Gopakumar, R., 2001: Geometry and String Theory, Current Science

81(12), 1568-1575

Gouts, A.K., 2003: The Theory of Multiverse - Multiplicity of Physical

Objects and Physical Constants, Gravitation and Cosmology 9, 33-36, , arXiv: gr-qc/0210072

Gray, J. / He, Y.-H. / Jejjala, V. / Nelson, B.D., 2005: The Geometry of

Particle Physics, arXiv: hep-th/0511062

Green, M.B., 1985: Unification of forces and particles in superstring theories, Nature 314, 409-414

Green, M.B., 1986: Superstrings, Scientific American 255/3, 44-56

Green, M.B., 1998: Connections between M-Theory and Superstrings,

Nuclear Physics Proceedings Supplement 68, 242-251, arXiv: hepth/9712195

Green, M.B. / Schwarz, J.H., 1981: Supersymmetrical Dual String Theory, Nuclear Physics B 181, 502-530; auch in: Schwarz (1985)

Green, M.B. / Schwarz, J.H., 1983: Superstring Interactions, Nuclear Physics B 218, 43-88; auch in: Schwarz (1985)

Green, M.B. / Schwarz, J.H., 1984: Superstring Field Theory, Nuclear Physics B 243, 475-536

Green, M.B. / Schwarz, J.H. / Brink, L., 1983: Superfield Theory of Type (II) Superstrings, Nuclear Physics B 219, 437-478; auch in: Schwarz (1985)

Green, M.B. / Schwarz, J.H. / Witten, E., 1987: Superstring Theory, 2 Vols., Cambridge

Greene, B., 1997: String Theory on Calabi-Yau-Manifolds, TASI-96

Summer School Lectures, in: Efthimiou / Greene (1997), arXiv: hepth/9702155

Greene, B., 1999: The Elegant Universe: Superstrings, Hidden Dimensions, and the Quest for the Ultimate Theory, New York (dt.: Das elegante Universum: Superstrings, verborgene Dimensionen und die Suche nach der Weltformel, Berlin, 2000) 
Greene, B., 2004: The Fabric of the Cosmos: Space, Time, and the Texture of Reality, New York (dt.: Der Stoff, aus dem der Kosmos ist - Raum, Zeit und die Beschaffenheit der Wirklichkeit, München, 2004)

Gross, D.J. / Harvey, J.R. / Martinec, E. / Rohm, R., 1985: Heterotic String Theory (I). The Free Heterotic String, Nuclear Physics B 256, 253284; auch in: Schwarz (1985)

Gouts, A.K., 2003: The Theory of Multiverse - Multiplicity of Physical

Objects and Physical Constants, Gravitation and Cosmology 9, 33-36, , arXiv: gr-qc/0210072

Guth, A.H., 2000, Inflation and Eternal Inflation, Physics Reports 333, 555-574, arXiv: astro-ph/0002156

Hanson, R., 2001: How to Live in a Simulation, Journal of Evolution and Technology 7, http://www.transhumanist.com

Hartle, J.B., 1995: Spacetime Quantum Mechanics and the Quantum Mechanics of Spacetime, in: B. Julia / J. Zinn-Justin (Eds.): Gravitation and Quantizations, Les Houches Summer School Proceedings LVII, Amsterdam, arXiv: gr-qc/9508023

Hartle, J.B., 1996: Scientific Knowledge from the Perspective of Quantum Cosmology, in: J.L. Casti / A. Karlqvist (Eds.): Boundaries and Barriers - On the Limits to Scientific Knowledge, Reading, Ma., arXiv: gr-qc/9601046

Hartle, J.B., 2003: The State of the Universe, in: G.W. Gibbons / E.P.S. Shellard / S.J. Ranken (Eds.): The Future of Theoretical Physics and Cosmology - Stephen Hawking 60th Birthday Symposium, Cambridge, arXiv: gr-qc/0209046

Hartle, J.B., 2004: Anthropic Reasoning and Quantum Cosmology, arXiv: hep-th/0406104

Hartle, J.B., 2005: Excess Baggage, arXiv: gr-qc/0508001

Hartle, J.B., 2006: Generalizing Quantum Mechanics for Quantum Spacetime, arXiv: gr-qc/0602013

Harvey, J.A., 1997: Magnetic Monopoles, Duality, and Supersymmetry, in: Efthimiou / Greene (1997), 157-216, arXiv: hep-th/9603086

Harvey, J. / Kachru, S. / Silverstein, E. (Eds.), 2001: Strings, Branes, and Gravity - TASI 99, Singapore

Hatfield, B.F., 1992: Quantum Field Theory of Point Particles and Strings, Reading, Mass.

Hawking, S.W., 1974: Black Hole Explosions, Nature 248, 30ff Hawking, S.W., 1975: Particle Creation by Black Holes, Communications in Mathematical Physics 43, 199-220 
Hawking, S.W., 1976: The Breakdown of Predictability in Gravitational Collapse, Physical Review D 14, 2460-2473

Hawking, S.W., 1980: Is the End in Sight for Theoretical Physics?, Cambridge

Hawking, S.W., 1982: The Unpredictability of Quantum Gravity, Communications in Mathematical Physics 87, 395-415

Hawking, S.W., 1993: A Brief History of Time, New York

Hawking, S.W., 2001: Future Science, Current Science 81(12), 1614-1616 Hawking, S.W., 2005: Information Loss in Black Holes, Physical Review

D 72, 084013, arXiv: hep-th/0507171

Hawking, S.W. / Hertog, T., 2002: Why does Inflation start at the Top of the Hill?, Physical Review D 66, 123509, arXiv: hep-th/0204212 Hawking, S.W. / Hertog, T., 2006: Populating the Landscape: A Top

Down Approach, Physical Review D 73, 123527, arXiv: hepth/0602091

Hawking, S.W. / Hertog, T. / Reall, H.S., 2000: Brane New World, Physical Review D 62, 043501, arXiv: hep-th/0003052

Hawking, S.W. / Penrose, R., 1998: Raum und Zeit, Reinbek

Hawking, S.W. / Thorne, K. / Novikov, I. / Ferris, T. / Lightman, A., 2002:

The Future of Spacetime, New York

Hedrich, R., 1990: Komplexe und fundamentale Strukturen - Grenzen des Reduktionismus, Mannheim / Wien / Zürich

Hedrich, R., 1993: Die nicht ganz so unglaubliche Effizienz der Mathematik in den Naturwissenschaften, Philosophia Naturalis 30/1, 106-125

Hedrich, R., 1994: Die Entdeckung der Komplexität - Skizzen einer strukturwissenschaftlichen Revolution, Frankfurt am Main / Thun Hedrich, R., 1995: Unsere epistemische Situation, ihre Grenzen und ihre neuronalen Determinanten - Der Objektbegriff, Philosophia Naturalis 32/1, 117-139

Hedrich, R., 1995a: Was ist eine physikalische Theorie ?, Praxis der Naturwissenschaften - Physik 1/44, 10-16

Hedrich, R., 1996: Artikel 'Naturphilosophie', in: P. Prechtl / F.-P. Burkard (Hrsg.): Metzler-Philosophie-Lexikon, Stuttgart, 2., erw. Aufl. (1999) Hedrich, R., 1996a: Artikel 'Physik', in: P. Prechtl / F.-P. Burkard (Hrsg.): Metzler-Philosophie-Lexikon, Stuttgart, 2., erw. Aufl. (1999)

Hedrich, R., 1998: Erkenntnis und Gehirn - Realität und phänomenale Welten innerhalb einer naturalistisch-synthetischen Erkenntnistheorie, Paderborn 
Hedrich, R., 1998a: Las bases materiales de nuestras capacidades epistémicas - Ensayo de una revisión sintética de la epistemología, Argumentos de Razón Técnica 1, 91-109

Hedrich, R., 1999: Die materialen Randbedingungen epistemischer Leistungen, Philosophia Naturalis 36/2, 237-262

Hedrich, R., 1999a: Artikel 'Naturwissenschaft', in: H.J. Sandkühler (Hrsg.): Enzyklopädie Philosophie, Hamburg, 930-933

Hedrich, R., 2001: The Naturalization of Epistemology and the

Neurosciences, Epistemologia - Rivista Italiana di Filosofia della

Scienza / An Italian Journal for the Philosophy of Science 24/2, 271300

Hedrich, R., 2002: Anforderungen an eine physikalische

Fundamentaltheorie, Zeitschrift für Allgemeine Wissenschaftstheorie /

Journal for General Philosophy of Science 33/1, 23-60

Hedrich, R., 2002a: Superstring Theory and Empirical Testability, http://philsci-archive.pitt.edu, Dokument PITT-PHIL-SCI00000608

Hedrich, R., 2002b: Epistemische Grenzen, in: W. Hogrebe (Hrsg.):

Grenzen und Grenzüberschreitungen - XIX. Deutscher Kongress für

Philosophie - Bonn 2002, Bonn, 317-327

Hedrich, R., 2002c: Zelluläre Automaten - Diskrete Modelle der Welt?, Philosophia Naturalis 39/1, 1-24

Hedrich, R., 2004: Beschleunigte Expansion und neue Kosmologie, Praxis der Naturwissenschaften - Physik 2/53, 25-29

Hedrich, R., 2005: In welcher Welt leben wir? - Superstrings, Kontingenz und Selektion, in: G. Abel (Hrsg.): Kreativität - XX. Deutscher Kongress für Philosophie - Sektionsbeiträge, Band 1,

Universitätsverlag der TU Berlin, Berlin (2005), S. 867-879

Hedrich, R., 2005a: In welcher Welt leben wir? - Physikalische

Vereinheitlichung, Kontingenz und Selektion im Superstring-Ansatz, in: W. Lütterfelds (Hrsg.): Vom Sinn und Unsinn des menschlichen Lebens, Universität Passau, Passau (2005), S. 5-26

Hedrich, R., 2006: String Theory - From Physics to Metaphysics, (i) erscheint in: Physics and Philosophy (Online-Zeitschrift); (ii) http://philsci-archive.pitt.edu, Dokument PITT-PHIL-SCI00002709; (iii) arXiv: physics/0604171

Hedrich, R., 2006a: The Internal and External Problems of String Theory A Philosophical View, (i) http://philsci-archive.pitt.edu, Dokument PITT-PHIL-SCI00003012; (ii) arXiv: physics/0610168 
Hedrich, R., 2007: Kohärenz und Kontingenz - Grundlagen der

Superstring-Theorie, in: B. Falkenburg (Hrsg.): Philosophie im interdisziplinären Dialog, Mentis Verlag, Paderborn (2007)

Hedrich, R. / Kuhn, W., 1989: Der drohende infinite Regress materieller

Strukturen, Praxis der Naturwissenschaften - Physik 7/38, 31-36;

wiederabgedruckt in: W. Kuhn: Physik: Erleben - Lehren - Lernen,

Aulis-Verlag Deubner, Köln (1993) S. 188-193

Hempel, C.G., 1969: Reduction: Ontological and Linguistic Facets, in: S.

Morgenbesser et al.: Philosophy, Science and Method. Essays in

Honor of Ernest Nagel, New York

Hilgevoord, J. (Ed.), 1995: Physics and Our View of the World, Cambridge Horava, P., 1999: M-Theory as a Holographic Field Theory, Physical

Review D 59, 046004, arXiv: hep-th/9712130

Horava, P. / Witten, E., 1996: Heterotic and Type I String Dynamics from

Eleven Dimensions, Nuclear Physics B 460, 506-524, arXiv: hepth/9510209

Horowitz, G.T., 1997: Quantum States of Black Holes, arXiv: grqc/9704072

Horowitz, G.T., 2005: Spacetime in String Theory, in: J. Pullin / R. Price

(Eds.): Spacetime 100 Years Later, arXiv: gr-qc/0410049

Horowitz, G.T. / Maldacena, J., 2004: The Black-Hole Final State, Journal of High Energy Physics 0402, 008, arXiv: hep-th/0310281

Horowitz, G.T. / Polchinski, J., 2006: Gauge/Gravity Duality, arXiv: grqc/0602037

Hu, B.L., 2005: Can Spacetime be a Condensate, International Journal of

Theoretical Physics 44, 1785-1806, arXiv: gr-qc/0503067

Hübsch, T., 1992: Calabi-Yau Manifolds - A Bestiary for Physicists, Singapore

Huggett, N. / Weingard, R., 1994: Interpretations of Quantum Field

Theory, Philosophy of Science 61, 370-388

Huggett, N. / Weingard, R., 1995: The Renormalization Group and

Effective Field Theories, Synthese 102, 171-194

Huggett, N. / Weingard, R., 1999: Gauge Fields, Gravity and Bohm's

Theory, in: T.Y. Cao (Ed.): Conceptual Foundations of Quantum

Field Theory, Cambridge, 287-297

Huggett, S.A. et al. (Eds.), 1998: The Geometric Universe, Oxford Hughes, S.A., 2005: Trust but verify: The case for astrophysical black holes, arXiv: hep-ph/0511217 
Hull, C.M. / Townsend, P.K., 1995: Unity of Superstring Dualities, Nuclear Physics B 438, 109, arXiv: hep-th/9410167

Ibanez, L.E., 2000: The Second String (Phenomenology) Revolution, Classical and Quantum Gravity 17, 1117-1128, arXiv: hep$\mathrm{ph} / 9911499$

Isham, C.J., 1981: Quantum Gravity - An Overview, in: Isham / Penrose / Sciama (1981) 1-62

Isham, C.J. / Penrose, R. / Sciama, D.W. (Eds.), 1975: Quantum Gravity. An Oxford Symposium, Oxford

Isham, C.J. / Penrose, R. / Sciama, D.W. (Eds.), 1981: Quantum Gravity 2. A Second Oxford Symposium, Oxford

Isham, C.J., 1993: Prima Facie Questions in Quantum Gravity, arXiv: grqc/9310031

Isham, C.J., 1995: Structural Issues in Quantum Gravity, arXiv: grqc/9510063

Isidro, J.M., 2005: A Quantum-Gravity Perspective on Semiclassical vs. Strong-Quantum Duality, arXiv: hep-th/0507150

Jacobson, T., 1999: On the Nature of Black Hole Entropy, arXiv: grqc/9908031

Jacobson, T. / Marolf, D. / Rovelli, C., 2005: Black Hole Entropy: inside or out?, International Journal of Theoretical Physics 44, 1807-1837, arXiv: hep-th/0501103

Johnson, C., 2002: D Branes, Cambridge

Jung, T., 2005: Universum und Multiversum - 'E pluribus unum'?, Philosophia Naturalis 42, 77-101

Kachru, S. / Kallosh, R. / Linde, A. / Trivedi, S.P., 2003: De Sitter Vacua in String Theory, Physical Review D 68, arXiv: hep-th/0301240

Kachru, S. / Kallosh, R. / Linde, A. / Maldacena, J. / McAllister, L. / Trivedi, S.P., 2003: Towards Inflation in String Theory, Journal of Cosmology and Astroparticle Physics 0310, 013, arXiv: hepth/0308055

Kaku, M., 1999: Introduction to Superstrings and M-Theory, 2nd Ed., New York

Kaku, M., 2000: Strings, Conformal Fields, and M-Theory, New York

Kallosh, R. / Linde, A., 2004: Landscape, the Scale of SUSY Breaking, and Inflation, Journal of High Energy Physics 0412, 004, arXiv: hepth/0411011

Kallosh, R. / Linde, A., 2006: Strings, Black Holes, and Quantum Information, Physical Review D 73, 104033, arXiv: hep-th/0602061 
Kallosh, R. / Prokushkin, S., 2004: Supercosmology, arXiv: hepth/0403060

Kaluza, T., 1921: Zum Unitätsproblem der Physik, Sitzungsberichte der Preussischen Akademie der Wissenschaften Berlin 1921, 967ff

Kane, G., 1997: String Theory is Testable, Even Supertestable, Physics Today 50/2, 40-42

Kemeny, J.G. / Oppenheim, P., 1956: On Reduction, Philosophical Studies 7, 6-19

Khoury, J. / Ovrut, B.A. / Steinhardt, P.J. / Turok, N., 2001: The Ekpyrotic Universe: Colliding Branes and the Origin of the Hot Big Bang, Physical Review D 64, 123522, arXiv: hep-th/0103239

Kiefer, C., 1994: Probleme der Quantengravitation, Philosophia Naturalis 31, 309-327

Kiefer, C., 2004: Quantum Gravity, Oxford Kiefer, C., 2005: Quantum Gravity: General Introduction and Recent Developments, Annalen der Physik 15, 129-148, arXiv: grqc/0508120

Kiritsis, E., 1997: Introduction to Superstring Theory, Leuven, auch: arXiv: hep-th/9709062

Kirshner, R., 2002: The Extravagant Universe: Exploding Stars, Dark Energy, and the Accelerating Cosmos, Princeton

Klebanov, I.R., 2001: TASI Lectures - Introduction to the AdS/CFT Correspondence, in: Harvey / Kachru / Silverstein (2001), arXiv: hepth/0009139

Klein, O., 1926: Quantentheorie und fünfdimensionale Relativitätstheorie, Zeitschrift für Physik 37, 895-906

Kobakhidze, A. / Mersini-Houghton, L., 2004: Birth of the Universe from the Landscape of String Theory, arXiv: hep-th/0410213

Kolb, E.W. / Seckel, D. / Turner, M.S., 1985: The Shadow World of Superstring Theories, Nature 314, 415-419

Krause, D., 2003: Structures and Structural Realism, http://philsciarchive.pitt.edu, Dokument PITT-PHIL-SCI00001558

Kribs, D.W. / Markopoulou, F., 2005: Geometry from Quantum Particles, arXiv: gr-qc/0510052

Krüger, L. 1983: Empirismus oder Realismus - eine Alternative in der Wissenschaftstheorie?, in: Beiträge XII. Deutscher Kongress für Philosophie, Innsbruck, 569-587

Kuhlmann, M., 2006: Quantum Field Theory, in: E.N. Zalta (Ed.): Stanford Encyclopedia of Philosophy, http://plato.stanford.edu 
Kuhlmann, M. / Lyre, H. / Wayne, A. (Eds.), 2002: Ontological Aspects of Quantum Field Theory, Singapore

Kuhlmann, M. / Lyre, H. / Wayne, A., 2002a: Introduction, in: dies. (2002)

Kumar, J., 2006: A Review of Distributions on the String Landscape,

arXiv: hep-th/0601053

Kutschera, F.v., 1989: Bemerkungen zur gegenwärtigen Realismus-

Diskussion, in: W.L. Gombocz et al.: Traditionen und Perspektiven der analytischen Philosophie, Wien

Ladyman, J., 1998: What is Structural Realism, Studies in the History and Philosophy of Science 29, 409-424

Lämmerzahl, C., 2004: General Relativity in Space and Sensitive Tests of the Equivalence Principle, arXiv: gr-qc/0402122

Laudan, L., 1981: A Confutation of Convergent Realism, Philosophy of

Science 48, 19-49

Laudan, L. / Leplin, J., 1991: Empirical Equivalence and

Underdetermination, Journal of Philosophy 88, 449-472

Leplin, J. (Ed.), 1984: Essays on Scientific Realism, Berkeley

Lemos, J.P.S., 2005: Black Holes and Fundamental Physics, arXiv: gr$\mathrm{qc} / 0507101$

Lerche, W., 2000: Recent Developments in String Theory, Wiesbaden; auch: arXiv: hep-th/9710246 (ältere Fassung)

Lifschytz, G., 1996: Comparing D-Branes to Black Branes, Physics Letters

B 388, 720, arXiv: hep-th/9604156

Liddle, A.R. / Ureña-López, L.A., 2006: Inflation, Dark Matter and Dark

Energy in the String Landscape, arXiv: astro-ph/0605205

Linde, A., 1984: The Inflationary Universe, Reports on Progress in

Physics 47, 925-986

Linde, A., 1990: Particle Physics and Inflationary Cosmology, Chur, auch: arXiv: hep-th/0503203

Linde, A., 2004: Inflation, Quantum Cosmology, and the Anthropic

Principle, in: Barrow / Davies / Harper (2004), 426-458

Lindley, D.: 1994, Das Ende der Physik - Vom Mythos der Grossen

Vereinheitlichten Theorie, Basel

Lloyd, S., 2005: The Computational Universe - Quantum Gravity from

Quantum Computation, arXiv: quant-ph/0501135

Lloyd, S., 2006: Almost Certain Escape from Black Holes, Physical

Review Letters 96, 061302, arXiv: quant-ph/0406205

Lu, H.Q. / Huang, Z.G. / Fang, W. / Zhang, K.F., 2004: Dark Energy and

Dilaton Cosmology, arXiv: hep-th/0409309 
Lüst, D. / Theisen, S., 1989: Lectures on String Theory, Lecture Notes in Physics 346, New York

Lyre, H., 2004: Lokale Symmetrien und Wirklichkeit. Eine naturphilosophische Studie über Eichtheorien und Strukturenrealismus, Paderborn Lyre, H., 2005: Metaphysik im 'Handumdrehen' - Kant und Earman, Parität und moderne Raumauffassung, Philosophia Naturalis 42, 49-76

Lyre, H. / Eynck, T.O., 2003: Curve it, Gauge it or Leave it? - Practical Underdetermination in Gravitational Theories, Journal for General Philosophy of Science 34, 277-303; auch: http://philsciarchive.pitt.edu, Dokument PITT-PHIL-SCI00000514

Mäkelä, J., 2006: Area and Entropy - A New Perspective, arXiv: grqc/0605098

Maldacena, J.M., 1996: Black Holes in String Theory, Ph.D. Thesis, arXiv: hep-th/9607235

Maldacena, J.M., 1998: Black Holes and D-Branes, Nuclear Physics Proceedings Supplement 61 A, 111, arXiv: hep-th/9705078

Maldacena, J.M., 1999: The Large N Limit of Superconformal Field Theories and Supergravity, International Journal of Theoretical Physics 38, 1113-1133

Maldacena, J.M., 2003: TASI 2003 Lectures on AdS/CFT, arXiv: hepth/0309246

Maldacena, J., 2004: Quantum Gravity as an Ordinary Gauge Theory, in: Barrow / Davies / Harper (2004), 153-166

Markopoulou, F., 2004: Planck-Scale Models of the Universe, in: Barrow / Davies / Harper (2004) 550-563, arXiv: gr-qc/0210086

Markopoulou, F. / Smolin, L., 1999: Holography in a Quantum Spacetime, arXiv: hep-th/9910146

Markopoulou, F. / Smolin, L., 2003: Quantum Theory from Quantum Gravity, Physical Review D 70, 124029, arXiv: gr-qc/0311059

Marolf, D., 2004: Resource Letter: The Nature and Status of String Theory, American Journal of Physics 72, 730, arXiv: hep-th/0311044

Matthews, R., 1994: Can Gravity Take a Quantum Leap?, New Scientist (10. Sep. 1994) 28-32

Maxwell, G., 1962: The Ontological Status of Theoretical Entities, Minnesota Studies in the Philosophy of Science 3, 7ff

Maudlin, T., 1993: Buckets of Water and Waves of Space: Why Spacetime is Probably a Substance, Philosophy of Science 60, 183-203

Maudlin, T., 2002: Quantum Non-locality and Relativity, Oxford McCabe, G., 2006: Possible Physical Universes, arXiv: gr-qc/0601073 
Mermin, D.J., 1990: Boojums All the Way Through, Cambridge Mersini-Houghton, L., 2005: WaveFunction of the Universe on the Landscape, arXiv: hep-th/0512304

Mersini-Houghton, L., 2006: Do We Have Evidence for New Physics in the Sky?, Modern Physics Letters A 21, 1-22, arXiv: hep-th/0510101

Meschini, D., 2006: Planck-Scale Physics - Facts and Beliefs, arXiv: grqc/0601097

Meschini, D. / Lehto, M., 2005: Is Empty Spacetime a Physical Thing?, arXiv: gr-qc/0506068

Meschini, D. / Lehto, M. / Piilonen, J., 2005: Geometry, Pregeometry and Beyond, Studies in History and Philosophy of Modern Physics 36, 435-464, arXiv: gr-qc/0411053

Misner, C.W. / Wheeler, J.A., 1957: Classical Physics as Geometry, Annals of Physics 2, 525-603

Misner, C.W. / Thorne, K.S. / Wheeler, J.A., 1973: Gravitation; San Francisco

Moffat, J.W., 1993: Do Black Holes Exist?, arXiv: gr-qc/9302032

Mohaupt, T., 2003: Introduction to String Theory, in: D. Giulini / C. Kiefer / C. Lämmerzahl (Eds.): Quantum Gravity - From Theory to

Experimental Search, Berlin, auch: arXiv: hep-th/0207249

Moortgat-Pick, G. / Zerwas, P.M., 2001: Supersymmetrie - der Weg zur grossen Vereinheitlichung?, Physikalische Blätter 57/3, 41-47

Moriyasu, K., 1983: An Elementary Primer for Gauge Theory, Singapore

Morrison, M., 2000: Unifying Scientific Theories. Physical Concepts and Mathematical Structures. Cambridge

Mukhi, S., 1997: Recent Developments in String Theory: A Brief Review for Particle Physicists, arXiv: hep-ph/9710470

Myers, R.C. / Pospelov, M., 2003: Experimental Challenges for Quantum Gravity, arXiv: gr-qc/0402028

Navarro, I. / Santiago, J., 2004: Flux Compactifications: Stability and Implications for Cosmology, Journal of Cosmology and Astroparticle Physics 0409, 005, arXiv: hep-th/0405173

Neveu, A. / Schwarz, J.H., 1971: Factorizable Dual Model of Pions, Nuclear Physics B 31, 86-112; auch in: Schwarz (1985)

Nielsen, H., 1983: Field Theories without Fundamental Gauge Symmetries, Philosophical Transactions of the Royal Society London

A 310, 261-272

Nielsen, H.B. / Rugh, S.E., 1994: Why do we live in 3+1 dimensions?, arXiv: hep-th/9407011 
Nielsen, H.B. / Rugh, S.E. / Surlykke, C., 1994: Seeking Inspiration from the Standard Model in order to go beyond it, arXiv: hep-th/9407012 Nobbenhuis, S., 2004: Categorzing Different Approaches to the Cosmological Constant Problem, arXiv: gr-qc/0411093

Norton, J.D., 1988: The Hole Argument, in: A. Fine / J. Leplin (Eds.): PSA 1988, Vol. 2, 56-64

Norton, J.D., 1993: The Determination of Theory by Evidence: The Case for Quantum Discontinuity, Synthese 97, 1-31

Norton, J.D., 1993a: General Covariance and the Foundations of General Relativity, Reports on Progress in Physics 56, 791-858

Norton, J.D., 1994: Science and Certainty, Synthese 99, 3-22

Norton, J.D., 2004: The Hole Argument, in: E.N. Zalta (Ed.): Stanford Encyclopedia of Philosophy, http://plato.stanford.edu

Ooguri, H. / Yin, Z., 1997: Lectures on Perturbative String Theories, in: Efthimiou / Greene (1997), 5-82, arXiv: hep-th/9612254

Ooguri, H. / Vafa, C., 2006: On the Geometry of the String Landscape and the Swampland, arXiv: hep-th/0605264

O'Raifeartaigh, L., 1995: The Dawning of Gauge Theory, Princeton

O'Raifeartaigh, L. / Straumann, N., 2000: Gauge Theory: Historical

Origins and Some Modern Developments, Reviews of Modern Physics 72/1, 1-23

Oriti, D., 2003: Spin Foam Models of Quantum Spacetime, Ph.D. Thesis, arXiv: gr-qc/0311066

Padmanabhan, T., 2003: Cosmological Constant - The Weight of the Vacuum, Physics Reports 380, 235-320, arXiv: hep-th/0212290

Peet, A.W., 1998: The Bekenstein Formula and String Theory, Classical and Quantum Gravity 15, 3291-3338, arXiv: hep-th/9712253

Peet, A.W., 2001: TASI Lectures on Black Holes in String Theory, in: Harvey / Kachru / Silverstein (2001), arXiv: hep-th/0008241

Penrose, R., 1967: Twistor Theory, Journal of Mathematical Physics 8, 345-366

Penrose, R., 2004: The Road to Reality. A Complete Guide to the Laws of the Universe, London

Penrose, R. / Isham, C.J. (Eds.), 1986: Quantum Concepts in Space and Time, Oxford

Per, M.A. / Segui, A., 2005: Holographic Cosmology and Uncertainty Relation, arXiv: gr-qc/0502025

Perez, A., 2003: Spin Foam Models for Quantum Gravity, Classical and Quantum Gravity 20, R43-R104, arXiv: gr-qc/0301113 
Piazza, F., 2005: Quantum Degrees of Freedom in a Region of Spacetime, arXiv: hep-th/0511285

Pierre, J., o.J.: Superstrings Home Page, http://www.sukidog.com/jpierre/strings

Pirogov, Y.F., 2005: Space-time: emerging vs. existing, arXiv: grqc/0503091

Pogosian, L. / Tegmark, M. / Vilenkin, A., 2004: Anthropic Predictions for Vacuum Energy and Neutrino Masses, Journal of Cosmology and Astroparticle Physics 0407, 005, arXiv: astro-ph/0404497

Poincaré, H., 1905: La Science et L'Hypothese, Paris

Polchinski, J.G., 1994: What is String Theory?, 1994 Les Houches Summer School Lectures, arXiv: hep-th/9411028

Polchinski, J.G., 1995: Dirichlet-Branes and Ramond-Ramond-Charges, Physical Review Letters 74, 4724-4727, arXiv: hep-th/9510017

Polchinski, J.G., 1996: String Duality, Reviews of Modern Physics 68, 1245-1258, arXiv: hep-th/9607050

Polchinski, J.G., 1996a: TASI Lectures on D-Branes, TASI-96 Summer School Lectures, arXiv: hep-th/9611050

Polchinski, J.G., 1999: Quantum Gravity at the Planck Length, International Journal of Modern Physics A14, 2633-2658, arXiv: hepth/9812104

Polchinski, J.G., 2000: String Theory. Vol. 1: An Introduction to the Bosonic String, Cambridge

Polchinski, J.G., 2000a: String Theory. Vol. 2: Superstring Theory and Beyond, Cambridge

Polchinski, J.G., 2006: The Cosmological Constant and the String Landscape, arXiv: hep-th/0603249

Polchinski, J.G. / Chaudhuri, S. / Johnson, C.V., 1996: Notes on D-Branes, arXiv: hep-th/9602052

Polyakov, A.M., 2006: Beyond Space-Time, arXiv: hep-th/0602011

Popper, K.R., 1935: Logik der Forschung, Wien

Popper, K.R., 1963: Truth, Rationality and the Growth of Scientific Knowledge, in: ders.: Conjectures and Refutations, London, Ch. 10, 215-248

Poundstone, W., 1985: The Recursive Universe - Cosmic Complexity and the Limits of Scientific Knowledge, Chicago

Preskill, J., 2000: Quantum Information and Physics: Some Future Directions, Journal of Modern Optics 47, 127-137, arXiv: quant-ph/9904022 
Psillos, S., 1995: Is Structural Realism the Best of Both Worlds?, Dialectica 49, 15-46

Psillos, S., 1996: Scientific Realism and the 'Pessimistic Induction', Philosophy of Science 63, S306-S314

Psillos, S., 1999: Scientific Realism. How Science Tracks Truth, London

Putnam, H., 1978: Realism and reason, in: ders.: Meaning and the moral sciences, London

Putnam, H., 1990: Realism with a human face, Cambridge, Mass.

Putnam, H., 1982: Vernunft, Wahrheit und Geschichte. Frankfurt am Main Putnam, H., 1982a: Why there isn't a ready-made world, Synthese 51, 141167

Putnam, H., 1984: What is Realism?, in: Leplin (1984)

Quevedo, F., 1996: Lectures on Superstring Phenomenology, in: J.C.

D'Olivo / A. Fernandez / M.A. Perez: Workshops on Particles and

Fields and Phenomenology of Fundamental Interactions, Puebla

1995, Woodbury, NY, 202-242, arXiv: hep-th/9603074

Quevedo, F., 2002: Lectures on String / Brane Cosmology, Classical and

Quantum Gravity 19, 5721-5779, arXiv: hep-th/0210292

Quine, W.V.O., 1953: Two Dogmas of Empiricism, in: ders.: From a

Logical Point of View, Cambridge, Ma.

Ramond, P., 1971: Dual Theory for Free Fermions, Physical Review D 3, 2415-2418; auch in: Schwarz (1985)

Ramond, P., 2003: Strings - Urbausteine der Natur?, Spektrum der

Wissenschaft (2/2003), 24-29

Randall, L. / Sundrum, R., 1999: An Alternative to Compactification,

Physical Review Letters 83, 4690-4693, arXiv: hep-th/9906064

Redhead, M., 1983: Quantum Field Theory for Philosophers, in: P.D.

Asquith / R.N. Giere: PSA 1982, Vol. 2, East Lansing, 57-99

Redhead, M., 1987: Incompleteness, Nonlocality and Realism, Oxford

Redhead, M., 1988: A Philosopher Looks at Quantum Field Theory, in:

Brown / Harré (1988)

Redhead, M., 1995: From Physics to Metaphysics, Cambridge

Redhead, M., 2002: The Interpretation of Gauge Symmetry, in: Kuhlmann / Lyre / Wayne (2002)

Rees, M.J., 2000: Just Six Numbers: The Deep Forces that Shape the

Universe, New York

Rees, M.J., 2001: Our Cosmic Habitat, Princeton

Renteln, P., 1991: Quantum Gravity, American Scientist 79, 508-527

Rescher, N., 1973: Conceptual Idealism, Oxford 
Rescher, N., 1973a: The Coherence Theory of Truth, Oxford

Rescher, N., 2000: The Price of an Ultimate Theory, Philosophia Naturalis

37, $1-20$

Rickles, D., 2005: Interpreting Quantum Gravity, http://philsciarchive.pitt.edu, Document: PITT-PHIL-SCI00002407

Rocek, M. / Wadhwa, N., 2005: On Calabi-Yau Supermanifolds, Advances in Theoretical and Mathematical Physics 9, 315-320, arXiv: hepth/0408188

Roush, S., 2003: Copernicus, Kant, and the Anthropic Cosmological Principle, Studies in History and Philosophy of Modern Physics 34, 5-35

Rovelli, C., 1997: Loop Quantum Gravity, Living Reviews in Relativity (Electronic Journal), http://www.livingreviews.org; auch: arXiv: grqc/9710008

Rovelli, C., 1998: Strings, Loops, and the Others: A Critical Survey on the Present Approaches to Quantum Gravity, in: N. Dadhich / J. Narlikar (Eds.): Gravitation and Relativity: At the Turn of the Millenium, Poona, arXiv: gr-qc/9803024

Rovelli, C., 1999: 'Localization' in Quantum Field Theory: How much of QFT is Compatible with What we Know about Space-Time?, in: T.Y.

Cao (Ed.): Conceptual Foundations of Quantum Field Theory,

Cambridge, 207-232

Rovelli, C., 2000: Notes for a Brief History of Quantum Gravity, arXiv: grqc/0006061

Rovelli, C., 2001: Quantum Spacetime: What do we know?, in: Callender / Huggett (2001); auch: arXiv: gr-qc/9903045 (ältere Fassung)

Rovelli, C., 2003: A Dialog on Quantum Gravity, International Journal of Modern Physics 12, 1, arXiv: hep-th/0310077

Rovelli, C., 2004: Quantum Gravity, Cambridge; auch:

http://www.cpt.univ-mrs.fr/ rovelli

Rovelli, C., 2005: What is Time? - What is Space? (Übers. a. d. Ital.: J.C. van den Berg), http://www.cpt.univ-mrs.fr/ rovelli

Rubakov, V.A., 2001: Large and Infinite Extra Dimensions, arXiv: hepth/0104152

Rucker, R., 1982: Infinity and the Mind, Boston

Rynasiewicz, R., 1994: The Lessons of the Hole Argument, British Journal for the Philosophy of Science 45, 407-436

Sagnotti, A., 1997: Surprises in Open String Perturbation Theory, Nuclear Physics Proceedings Supplement 56 B, 332, arXiv: hep-th/9702093 
Sanchez, N.G., 2003: Advances in String Theory in Curved Backgrounds:

A Synthesis Report, International Journal of Modern Physics A 18, 2011-2024, arXiv: hep-th/0302228

Saunders, S., 2003: Critical Notice: Tian Yu Cao's 'The Conceptual Development of 20th Century Field Theories', Synthese 136/1, 79-105

Saunders, S., 2003a: Structural Realism, again, Synthese 136/1, 127-133

Saunders, S. / Brown, H.R. (Eds.), 1991: The Philosophy of Vacuum, Oxford

Satheesh Kumar, V.H. / Suresh, P.K., 2005: Are we Living in a Higher

Dimensional Universe?, arXiv: gr-qc/0506125

Scheibe, E., 2001: Between Rationalism and Empiricism. Selected Papers in the Philosophy of Physics, New York

Scherk, J. / Schwarz, J.H., 1974: Dual Models for Non-Hadrons, Nuclear Physics B 81, 118-144; auch in: Schwarz (1985)

Schmidhuber, J., 1997: A Computer Scientist's View of Life, the Universe, and Everything, in: C. Freksa (Ed.): Foundations of Computer

Science: Potential - Theory - Cognition, Lecture Notes in Computer

Science, Berlin, 201-208, arXiv: quant-ph/9904050

Schnitzer, H.J., 2003: String Theory - A Theory in Search of an

Experiment, arXiv: physics/0311047

Schroer, B., 2006: String Theory and the Crisis in Particle Physics, arXiv: physics/0603112

Schwarz, A., 2006: Space and Time from Translation Symmetry, arXiv: hep-th/0601035

Schwarz, J.H., 1982: Superstring Theory, Physics Reports 89, 223-322; auch in: Schwarz (1985)

Schwarz, J.H., 1984: What are Superstrings?, Comments on Nuclear Particle Physics 13/3, 102-115

Schwarz, J.H. (Ed.), 1985: Superstrings: The First 15 Years of Superstring Theory, 2 Vols., Singapore

Schwarz, J.H., 1987: Superstrings, Physics Today 40/11, 33-40

Schwarz, J.H., 1996: The Power of M-theory, Physics Letters B 367, 97 103, arXiv: hep-th/9510086

Schwarz, J.H., 1997: Lectures on Superstring and M Theory Dualities, in:

Efthimiou / Greene (1997), 359-418, arXiv: hep-th/9607201

Schwarz, J.H., 1998: Beyond Gauge Theories, arXiv: hep-th/9807195

Schwarz, J.H., 2000: Introduction to Superstring Theory, arXiv: hepex/0008017

Schwarz, J.H,, 2001: String Theory, Current Science 81(12), 1547-1553 
Schwarz, P., o.J.: The Official String Theory Web Site, http://superstringtheory.com

Scott, D. / Zibin, J.P., 2006: How many Universes do there need to be?, arXiv: astro-ph/0605709

Segal, G., 1998: Space from the Point of View of Loop Groops, in: S.A. Huggett et al. (Eds.): The Geometric Universe, Oxford (1998)

Seiberg, N., 2006: Emergent Spacetime, arXiv: hep-th/0601234

Sen, A., 1982: Gravity as a Spin System, Physics Letters B 11, 89ff

Sen, A., 1996: U-Duality and Intersecting D-Branes, Physical Review D 53, 2874ff, arXiv: hep-th/9511026

Sen, A., 1997: Unification of String Dualities, Nuclear Physics Proceedings Supplement 58, 5, arXiv: hep-th/9609176

Sen, A., 1998: An Introduction to Non-perturbative String Theory, arXiv: hep-ph/9802051

Sen, A., 1998a: Developments in Superstring Theory, arXiv: hep$\mathrm{ph} / 9810356$

Sen, A., 1998b: String Network, Journal of High Energy Physics 9803, 005, arXiv: hep-th/9711130

Sen, A., 2001: String Theory and Tachyons, Current Science 81(12), 15611567

Shenker, S.H., 1995: Another Length Scale in String Theory, arXiv: hepth/9509132

Shimony, A, 1999: Can the fundamental laws of nature be the results of evolution?, in: Butterfield / Pagonis (1999)

Siegel, W., 1989: Introduction to String Field Theory, Singapore, auch: arXiv: hep-th/0107094

Siegfried, T., 2000: The Bit and the Pendulum: From Quantum Computing to $M$ Theory - The New Physics of Information, New York

Sloterdijk, P. / Macho, T.H. (Hrsg.), 1991: Weltrevolution der Seele, 2 Bände, München

Smolin, L., 1997: The Life of the Cosmos, Oxford (dt.: Warum gibt es die Welt? - Die Evolution des Kosmos, München, 1999)

Smolin, L., 1998: Towards a background independent approach to M theory, arXiv: hep-th/9808192

Smolin, L., 2000: Three Roads to Quantum Gravity, London

Smolin, L., 2000a: Strings as Perturbations of Evolving Spin-networks, Nuclear Physics Proceedings Supplement 88, 103-113, arXiv: hepth/9801022 
Smolin, L., 2000b: A Candidate for a Background Independent

Formulation of M Theory, Physical Review D 62, 086001, arXiv: hepth/9903166

Smolin, L., 2001: The Strong and the Weak Holographic Principles,

Nuclear Physics B 601, 209, arXiv: hep-th/0003056

Smolin, L., 2002: Quantum Gravity with a Positive Cosmological

Constant, arXiv: hep-th/0209079

Smolin, L., 2002a: Technical Summary of Loop Quantum Gravity, http://www.qgravity.org/loop

Smolin, L., 2003: How far are we from the quantum theory of gravity?, arXiv: hep-th/0303185

Smolin, L., 2004: Scientific Alternatives to the Anthropic Principle, arXiv: hep-th/0407213

Smolin, L., 2004a: Quanten der Raumzeit, Spektrum der Wissenschaft (3/2004), 54-63

Smolin, L., 2004b: An Invitation to Loop Quantum Gravity, arXiv: hepth/0408048

Smolin, L., 2004c: Quantum Theories of Gravity: Results and Prospects, in: Barrow / Davies / Harper (2004) 492-527

Smolin, L., 2005: The Case for Background Independence, arXiv: hepth/0507235

Smolin, L., 2006: Generic Predictions of Quantum Theories of Gravity, arXiv: hep-th/0605052

Smolin, J.A. / Oppenheim, J., 2006: Information Locking in Black Holes, Physical Review Letters 96, 081302, arXiv: hep-th/0507287

Sorkin, R.D., 1997: Forks on the Road on the Way to Quantum Gravity, International Journal of Theoretical Physics 36, 2757-2781, arXiv: gr-qc/9706002

Sorkin, R.D., 2005: Ten Theses on Black Hole Entropy, Studies in History and Philosophy of Modern Physics 36, 291-301, arXiv: hepth/0504037

Stachel, J., 2005: Structure, Individuality and Quantum Gravity, arXiv: grqc/0507078

Steinhardt, P.J. / Turok, N., 2002: A Cyclic Model of the Universe, Science 296, 1436-1439, arXiv: hep-th/0111030

Steinhardt, P.J. / Turok, N., 2002a: Cosmic Evolution in a Cyclic Universe, Physical Review D 65, 126003, arXiv: hep-th/0111098

Stöckler, M., 1987: Philosophische Probleme der Elementarteilchenphysik, Habilitationsschrift, Universität Giessen 
Stöckler, M., 1998: On the Unity of Physics in a Dappled World -

Comment on Nancy Cartwright, Philosophia Naturalis 35, 35-39

Stoeger, W.R., 2006: Retroduction, Multiverse Hypotheses and Their

Testability, arXiv: astro-ph/0602356

Stoeger, W.R. / Ellis, G.F. / Kirchner, U., 2004: Multiverses and

Cosmology - Philosophical Issues, arXiv: astro-ph/0407329

Strassler, M.J., 2003: An Unorthodox Introduction to Supersymmetric

Gauge Theory, arXiv: hep-th/0309149

Strominger, A., 1996: Open p-Branes, Physics Letters B 383, 44, arXiv: hep-th/9512059

Strominger, A. / Vafa, C., 1996: Microscopic Origin of the Bekenstein-

Hawking Entropy, Physics Letters B 379, 99-104, arXiv: hepth/9601029

Strominger, A. / Yau, S.-T. / Zaslow, E., 1996: Mirrow Symmetry is T-

Duality, Nuclear Physics B 479, 243, arXiv: hep-th/9606040

Susskind, L., 1995: The World as a Hologram, Journal of Mathematical

Physics 36, 6377-6396, arXiv: hep-th/9409089

Susskind, L., 2003: The Anthropic Landscape of String Theory, arXiv:

hep-th/0302219

Susskind, L., 2004: Supersymmetry Breaking in the Anthropic Landscape, arXiv: hep-th/0405189

Susskind, L., 2004a: Cosmic Natural Selection, arXiv: hep-th/0407266

Susskind, L., 2005: The Cosmic Landscape - String Theory and the Illusion of Intelligent Design, New York

Taubes, G., 1995: A Theory of Everything Takes Shape, Science 269, 1511-1513

Taubes, G., 1999: String Theorists find a Rosetta Stone, Science 285, 512517

Tavakol, R. / Ellis, G., 1999: On Holography and Cosmology, Physics

Letters B 469, 37-45, arXiv: hep-th/9908093

Taylor, W., 2001: M(atrix) Theory - Matrix Quantum Mechanics as a

Fundamental Theory, Reviews of Modern Physics 73, 419-462, arXiv:

hep-th/0101126

Taylor, W., 2006: String Field Theory, arXiv: hep-th/0605202

Taylor, W. / Zwiebach, B., 2003: D-Branes, Tachyons and String Field

Theory, arXiv: hep-th/0311017

Tegmark, M., 1996: Does the Universe in Fact contain almost no

Information?, Foundations of Physics Letters 9, 25-42, arXiv: quantph/9603008 
Tegmark, M., 1998: Is 'the Theory of Everything' Merely the Ultimate

Ensemble Theory?, Annals of Physics 270, 1-51, arXiv: gr-

qc/9704009

Tegmark, M., 2004: Parallel Universes, in: Barrow / Davies / Harper (2004) 459-491, arXiv: astro-ph/0302131

Tegmark, M., 2003: Paralleluniversen, Spektrum der Wissenschaft (8/2003), 34-45

Tegmark, M., 2005: What does Inflation really predict?, Journal of Cosmology and Astroparticle Physics 0504, 001, arXiv: astro$\mathrm{ph} / 0410281$

Tegmark, M. / Aguirre, A. / Rees, M.J. / Wilczek, F., 2006: Dimensionless Constants, Cosmology and other Dark Matters, Physical Review D 73, 023505, arXiv: astro-ph/0511774

Teller, P., 1995: An Interpretative Introduction to Quantum Field Theory, Princeton, N.J.

Teramond, G.F.de, 1999, Possible origin of fermion chirality and GUT structure from extra dimensions, Physical Review D 60

Terno, D.R., 2005: From Qubits to Black Holes: Entropy, Entanglement and all that, International Journal of Modern Physics D 14, 23072314, arXiv: gr-qc/0505068

Thiemann, T., 2001: Introduction to Modern Canonical Quantum General Relativity, arXiv: gr-qc/0110034

't Hooft, G., 1993: Dimensional Reduction in Quantum Gravity, arXiv: grqc/9310026

't Hooft, G., 1995: Questioning the Answers or Stumbling upon Good and Bad Theories of Everything, in: Hilgevoord (1995)

't Hooft, G., 2000: The Holographic Principle, arXiv: hep-th/0003004

't Hooft, G., 2001: How does God play dice? - (Pre-)Determinism at the Planck-Scale, arXiv: hep-th/0104219

't Hooft, G., 2001a: Obstacles on the Way Towards the Quantisation of Space, Time and Matter - and Possible Resolutions, Studies in the History and Philosophy of Modern Physics 32, 157-180

Tipler, F.J., 1994: The Physics of Immortality, London, MacMillan Townsend, P.K., 1995: The eleven-dimensional supermembrane revisited, Physics Letters B 350, 184-187, arXiv: hep-th/9501068

Townsend, P.K., 1995a: P-Brane Democracy, arXiv: hep-th/9507048

Townsend, P.K., 1996: Four Lectures on M-Theory, in: E. Gava et al. (Eds.): High-Energy Physics and Cosmology, Trieste 1996, Singapore, 385-438, arXiv: hep-th/9612121 
Trivedi, S.P., 2001: Holography, Black Holes and String Theory, Current Science 81(12), 1582-1590

Troost, J., o.J.: Beyond String Theory, http://tena4.vub.ac.be/beyondstringtheory

Turok, N. / Steinhardt, P.J., 2002: The Cyclic Universe - An Informal Introduction, arXiv: astro-ph/0204479

Turok, N. / Steinhardt, P.J., 2005: The Cyclic Model Simplified, New Astronomical Review 49, 43-57, arXiv: astro-ph/0404480

Tye, S.H.H., 1995: Status of Fractional Superstrings, in: M.B. Halpern / G. Rivlis / A. Sevrin: Proceedings of Strings '93, Singapore, 364-378, arXiv: hep-th/9311021

Unruh, W.G., 2001: Black Holes, Dumb Holes, and Entropy, in: Callender / Huggett (2001)

Vaas, R., 2004: Das Duell: Strings gegen Schleifen, Bild der Wissenschaft (4/2004), 44-49

Vafa, C., 1997: Lectures on Strings and Dualities, 1996 ICTP Summer School Lectures, arXiv: hep-th/9702201

Vafa, C., 2005: The String Landscape and the Swampland, arXiv: hepth/0509212

Van Fraassen, B.C., 1980: The Scientific Image, Oxford

Velo, G. / Wightman, A.S. (Eds.), 1976: Renormalization Theory, Dordrecht

Veneziano, G., 1998: A simple/short introduction to pre-big bang physics/cosmology, arXiv: hep-th/9802057

Veneziano, G., 2004: Die Zeit vor dem Urknall, Spektrum der Wissenschaft (8/2004), 30-39

Vilenkin, A., 2004: Anthropic Predictions - The Case of the Cosmological Constant, arXiv: astro-ph/0407586

Virasoro, M.A., 1970: Subsidiary Conditions and Ghosts in DualResonance Models, Physical Review D 1, 2933-2936

Wadia, S.R., 2001: A Microscopic Theory of Black Holes in String Theory - Thermodynamics and Hawking Radiation, Current Science 81(12), 1591-1597

Wald, R.M., 1994: Quantum Field Theory on Curved Spacetime and Black Hole Thermodynamics, Chicago

Wald, R.M., 2001: The Thermodynamics of Black Holes, Living Reviews in Relativity (Electronic Journal) 4/6, http://www.livingreviews.org; auch: arXiv: gr-qc/9912119 
Ward, R.S., 1998: Twistors, Geometry, and Integrable Systems, in: S.A. Huggett et al. (Eds.): The Geometric Universe, Oxford (1998)

Wang, C.H.-T., 2006: New "Phase" of Quantum Gravity, arXiv: gr$\mathrm{qc} / 0605124$

Weinberg, S., 1977: The Search for Unity: Notes for a History of Quantum Field Theory, Daedalus 106/4, 17-35

Weinberg, S., 1987: Anthropic Bound on the Cosmological Constant, Physical Review Letters 59, 2607ff

Weinberg, S., 1989: The Cosmological Constant Problem, Reviews of Modern Physics 61, 1-23

Weinberg, S., 1992: Dreams of a Final Theory, New York (dt.: Der Traum von der Einheit des Universums, München, 1993)

Weinberg, S., 2000: The Cosmological Constant Problems, arXiv: astro$\mathrm{ph} / 0005265$

Weinberg, S., 2005: Living in a Multiverse, arXiv: hep-th/0511037

Weingard, R., 1989: A Philosopher looks at String Theory, Proceedings of the Philosophy of Science Association 1988, Vol. 2, Chicago, 95-106, auch in: Callender / Huggett (2001)

Weinstein, S., 1998: Conceptual and Foundational Issues in the Quantization of Gravity, Dissertation, Northwestern University, Evanston, Il.

Weinstein, S., 1999: Gravity and Gauge Theory, Philosophy of Science 66, Supplement (Proceedings), S146-S155

Weinstein, S., 2001: Naive Quantum Gravity, in: Callender / Huggett (2001)

Weinstein, S., 2005: Quantum Gravity, in: E.N. Zalta (Ed.): Stanford Encyclopedia of Philosophy, http://plato.stanford.edu

Weinstein, S., 2006: Anthropic Reasoning in Multiverse Cosmology and String Theory, Classical and Quantum Gravity 23, 4231-4236, arXiv: hep-th/0508006

Wess, J. / Zumino, B., 1974: Supergauge Transformations in Four Dimensions, Nuclear Physics B 70, 39-50

Wesson, P.S., 1998: Space - Time - Matter: Modern Kaluza-Klein Theory, Singapore

Wheeler, J.A., 1957: On the Nature of Quantum Geometrodynamics, Annals of Physics 2, 604-614

Wheeler, J.A., 1962: Geometrodynamics, New York

Wheeler, J.A., 1973: Beyond the End of Time, in: C.W. Misner / K.S.

Thorne / J.A. Wheeler: Gravitation; San Francisco, 1196-1217 
Wheeler, J.A., 1979: Frontiers of Time, in: N. Toraldo di Francia (Ed.):

Problems in the Foundations of Physics. Proceedings of the Interna-

tional School of Physics 'Enrico Fermi', Course 72, Amsterdam

Wheeler, J.A., 1983: Law without Law, in: J.A. Wheeler / W.H. Zurek

(Eds.): Quantum Theory and Measurement, Princeton, N.J.

Wheeler, J.A., 1989: Information, Physics, Quantum: the Search for Links,

in: Proceedings 3rd International Symposium on the Foundation of

Quantum Mechanics, Tokyo, 354-368; auch in: W.H. Zurek (Ed.):

Complexity, Entropy and the Physics of Information, New York (1990), 3-28

Wheeler, J.A., 1991: Gravitation und Raumzeit - Die vierdimensionale

Ereigniswelt der Relativitätstheorie, Heidelberg

Wheeler, J.A. / Ford, K., 1998: Black Holes and Quantum Foam: A Life in

Physics, New York

Willaschek, M. (Hg.), 2000: Realismus, Paderborn

Wilczek, F., 2005: Enlightenment, Knowledge, Ignorance, Temptation, arXiv: hep-th/0512187

Wilczek, F., 2006: The Universe as a Strange Place, International Journal of Modern Physics A 21, 2011, arXiv: physics/0511067

Witten, E., 1985, Dimensional Reduction of Superstring Models, Physics Letters B 155, 151-155

Witten, E., 1993: Quantum background independence in string theory, arXiv: hep-th/9306122

Witten, E., 1995: String Theory Dynamics in Various Dimensions, Nuclear Physics B 443, 85-126, arXiv: hep-th/9503124

Witten, E., 1996: Reflections on the Fate of Spacetime, Physics Today

49/4, 24-30; auch in: Callender / Huggett (2001)

Witten, E., 1996a: Bound States of Strings and p-Branes, Nuclear Physics B4 60, 335, arXiv: hep-th/9510135

Witten, E., 1996b: Strong Coupling Expansion of Calabi-Yau Compactification, Nuclear Physics B 471, 135, arXiv: hep-th/9602070

Witten, E., 1997: Duality, Spacetime and Quantum Mechanics, Physics Today 50/5, 28-33

Witten, E., 2001: Black Holes and Quark Confinement, Current Science 81(12), 1576-1581

Wolfram, S., 2002: A New Kind of Science, Champaign, Ill.

Woit, P., 2001: String Theory - An Evaluation, arXiv: physics/0102051 Woit, P., 2002, Is String Theory Even Wrong?, American Scientist 90, $110-112$ 
Worrall, J., 1989: Structual Realism: The Best of Both Worlds?, Dialectica 43, 99-124

Wüthrich, C., 2003: Quantum Gravity and the 3D vs. 4D Controversy, http://alcor.concordia.ca/ scol/seminars/conference/Wuthrich.pdf Yoneya, T., 2001: String Theory and the Uncertainty Principle, Current Science 81(12), 1554-1560

Zeh, H.D., 2005: Where has all the Information gone?, Physics Letters A 347, 1-7, arXiv: gr-qc/0507051

Zizzi, P.A., 2001: Quantum Computation toward Quantum Gravity, General Relativity and Gravitation 33, 1305-1318, arXiv: grqc/0008049

Zizzi, P.A., 2005: A Minimal Model for Quantum Gravity, Modern Physics Letters A 20, 645-653, arXiv: gr-qc/0409069

Zumino, B., 1979: Supersymmetry - A Way to the Unitary Field Theory, in: H. Nelkowski et al. (Eds.): Einstein Symposium Berlin, Berlin (1979)

Zurek, W., 2004: Quantum Darwinism and Envariance, in: Barrow / Davies / Harper (2004)

Zwiebach, B., 2004: A First Course in String Theory, Cambridge

-, 2001: Superstrings - A Quest for a Unified Theory, Special Section, Current Science 81(12)

-, 2003: Quantum Gravity, Special Section, Physics World 16 (11/2003) 